\title{
ChemComm
}

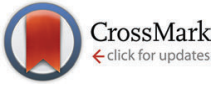

Cite this: Chem. Commun., 2015, 51, 12243

Received 20th February 2015, Accepted 23rd June 2015

DOI: $10.1039 / c 5 c c 01563 d$

www.rsc.org/chemcomm

\section{DNA modulates solvent isotope effects in a nanopore $\dagger$}

\author{
Matthew A. Watson and Scott L. Cockroft*
}

\begin{abstract}
Here we investigate the modulation of solvent isotope effects by the entry of DNA molecules into individual $\alpha$-haemolysin nanopores. Solvent isotope effects in $\mathrm{D}_{2} \mathrm{O}$ versus $\mathrm{H}_{2} \mathrm{O}$ were enhanced $\left(k_{\mathrm{H}} / k_{\mathrm{D}} \approx 1.6\right)$ compared to the bulk $\left(k_{\mathrm{H}} / k_{\mathrm{D}} \approx 1.2\right)$, except when the pore was most blocked $\left(k_{\mathrm{H}} / k_{\mathrm{D}} \leq 1.1\right)$.
\end{abstract}

Isotopic substitution experiments in which one or more hydrogen atoms are replaced with the heavier isotope deuterium are well established as a means of investigating reaction mechanisms. ${ }^{1,2}$ These so-called kinetic isotope effects (as defined by $k_{\mathrm{H}} / k_{\mathrm{D}}$ ), have origins in the vibrational differences in protiated versus deuterated bonds. ${ }^{3}$ Special cases have also been identified in synthetic host-guest and catalytic systems where more unusual steric and equilibrium isotope effects are exhibited. ${ }^{4-7}$ Meanwhile in the supramolecular chemistry of life, organisms can distinguish between deuterated and non-deuterated analogues of small molecules, but the mechanisms of these recognition processes are controversial. ${ }^{8,9}$ Furthermore, isotope effects can have a profound influence on the bulk physical properties of solvents. ${ }^{10}$ For example, the melting and boiling points of $\mathrm{D}_{2} \mathrm{O}$ and $\mathrm{H}_{2} \mathrm{O}$ differ by a few degrees, which might account for the enrichment of $\mathrm{D}_{2} \mathrm{O}$ relative to $\mathrm{H}_{2} \mathrm{O}$ on comets compared to Earth. ${ }^{11-13}$ Perhaps even more striking is the viscosity of $\mathrm{D}_{2} \mathrm{O}$, which is $23 \%$ higher than $\mathrm{H}_{2} \mathrm{O}$. This is significant on the nanoscale because the dynamic behaviour of biological molecular machines is dominated by Brownian motion and solvent viscosity. ${ }^{14,15}$ Experiments have shown that proteins behave differently in $\mathrm{D}_{2} \mathrm{O}$ compared to $\mathrm{H}_{2} \mathrm{O},{ }^{16,17}$ while the effect of $\mathrm{D}_{2} \mathrm{O}$ on various biological ion channels has also been examined at the ensemble level via electrophysiological methods. ${ }^{18-20}$ However, little is known about how solvent isotope effects change in the transition between the bulk and nanoscale regimes,

EaStCHEM School of Chemistry, University of Edinburgh, Joseph Black Building, David Brewster Road, Edinburgh, EH9 3FJ, UK. E-mail: scott.cockroft@ed.ac.uk $\dagger$ Electronic supplementary information (ESI) available: Detailed experimental procedures for single channel experiments, synthesis and purification of DNA, experimental materials, and tabulated data. See DOI: 10.1039/c5cc01563d particularly given the propensity for unusual behaviour to emerge at greatly reduced dimensions. ${ }^{21,22}$

Here we have examined the nanoscale modulation of solvent isotope effects on transmembrane ion currents due to the entry of single-stranded DNA into individual transmembrane $\alpha$-haemolysin $(\alpha-\mathrm{HL})$ nanopores (Fig. 1 and 2). ${ }^{23}$ The isotope effects observed on the nanoscale were compared with the equivalent processes occurring at macroscopic levels (Fig. 3). The modulation of the isotope effect on the transmembrane ion current was found to be strongly dependent on the extent of the current blockage during DNA events (Fig. 4).

$\alpha$-Haemolysin nanopores have been used to investigate a wide range of processes at the single-molecule level including chemical reactions, ${ }^{24,25}$ enzyme activity, ${ }^{26-29}$ the analysis of nucleic acids, ${ }^{30-35}$ and of most relevance to the present work, kinetic isotope effects in reactions ${ }^{36}$ and differences in protonation dynamics in $\mathrm{D}_{2} \mathrm{O}$ versus $\mathrm{H}_{2} \mathrm{O} .^{37}$ Furthermore, strategies such as changing solvent viscosity to modulate the translocation of

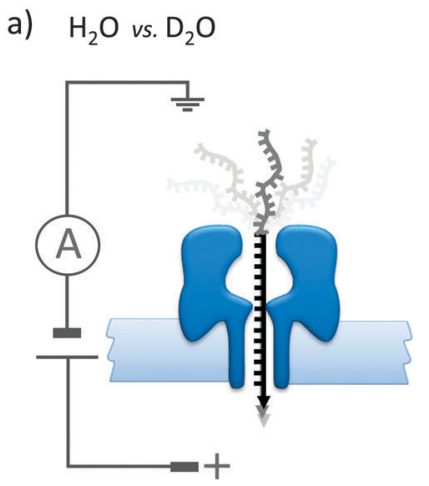

b) Translocation events

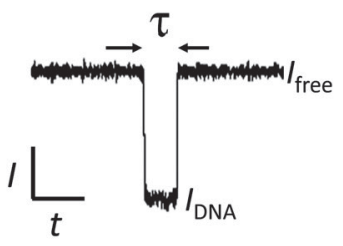

c) Residual current

$$
l^{*}=\frac{I_{\mathrm{DNA}}}{l_{\text {free }}}
$$

Fig. 1 (a) Experimental set-up used to determine solvent isotope effects on the ionic currents flowing through an individual $\alpha$-haemolysin $(\alpha-\mathrm{HL})$ channel. (b) and (c) representative data and equation used to determine the residual current $\left(/^{\star}\right)$ and the lifetime $(\tau)$ of blockages occurring during events in which single-stranded DNA enters the pore. IDNA is the ion current during DNA events $\left(3^{\prime}\right.$ - or $5^{\prime}$ - first translocation, or events in which the DNA enters the vestibule of the pore). 


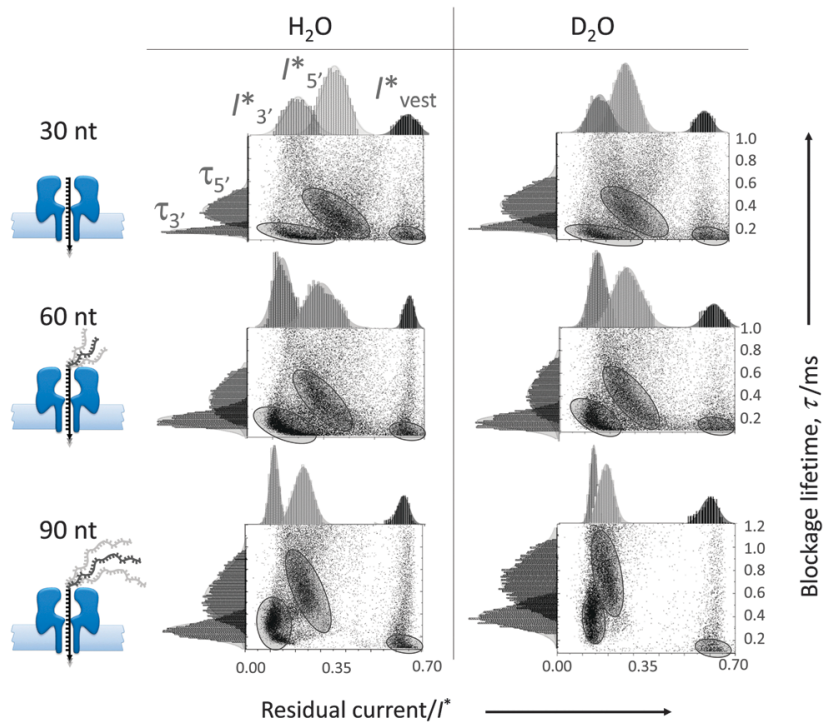

Fig. 2 Comparative scatter plots showing individual events in which DNA either entered or translocated the nanopore for different lengths of singlestranded poly dT DNA in $\mathrm{H}_{2} \mathrm{O}$ and $\mathrm{D}_{2} \mathrm{O}$ buffer. Each scatterplot was compiled from events recorded in at least five different single-channel experiments. $1^{*}$ is the residual current during DNA events and $\tau$ is the blockage lifetime (Fig. 1). The ${ }^{*}$ subscripts indicate either $3^{\prime}$ - or $5^{\prime}$-first translocation, or vestibule events. ${ }^{35}$ The standard deviations in the property distributions of the single-molecule measurements are provided in Table S1 in the ESI. $\dagger$
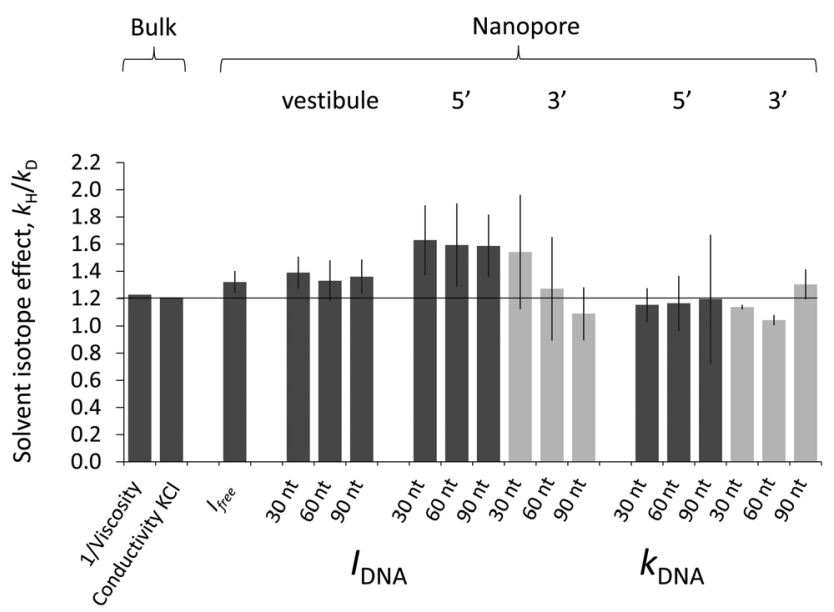

Fig. 3 Comparison of solvent isotope effects observed in bulk solution ${ }^{11,12}$ and in single-molecule nanopore experiments. All average current values (I) and the average rate of voltage-driven DNA translocation ( $\left.k_{\mathrm{DNA}}\right)$ through individual nanopores were determined from the data represented in Fig. 2. The "error bars" indicate the standard deviation across thousands of single-molecule measurements (as seen in the scatterplots in Fig. 2), rather than the much smaller experimental errors associated with the current recordings. Labels indicate data corresponding to either $5^{\prime}$-first and $3^{\prime}$-first DNA translocations, or vestibule events in which the DNA entered but did not translocate the pore. The data show the relative modulation of the solvent isotope effect on ion transport in the free nanopore and during vestibule events $\left(k_{H} / k_{D}=1.3\right.$ to 1.4$)$ compared to bulk solution $\left(k_{H} / k_{D}=1.2\right)$. During DNA translocation events the solvent isotope effect is greatly enhanced in some cases $\left(k_{H} / k_{D} \leq 1.6\right)$ but not in others.

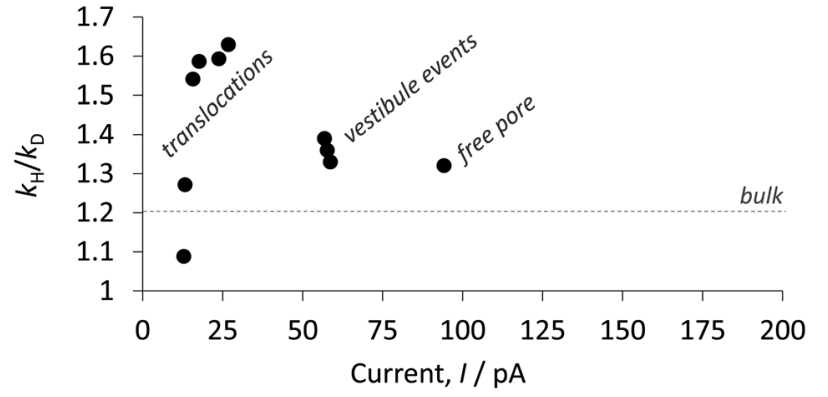

Fig. 4 The relationship between the solvent isotope effect $\left(k_{H} / k_{D}\right)$ observed in $\alpha$-haemolysin nanopores and the transmembrane ion current flowing through the channel (values of $I_{\text {DNA }}$ and $I_{\text {free }}$ in $\mathrm{H}_{2} \mathrm{O}$ buffer are plotted).

DNA through nanopores have been examined for potential applications in nanopore-based DNA sequencing. ${ }^{38-40}$

The effects of $\mathrm{D}_{2} \mathrm{O}$ on ion transport and the translocation of single-stranded DNA molecules through individual $\alpha$-HL nanopores have not been investigated despite the potential to offer unique insights into the influence of solvent structure and dynamics on non-equilibrium processes. Thus, we set out to perform such an investigation using the experimental platform shown in Fig. 1. In this setup, a planar bilayer was suspended in a $100 \mu \mathrm{m}$ aperture separating two wells of buffered electrolyte solution. The buffers used were either $1 \mathrm{M} \mathrm{KCl,} 25 \mathrm{mM}$ Tris $\mathrm{HCl}$, in $\mathrm{H}_{2} \mathrm{O}$ at $\mathrm{pH}$ 8, or $1 \mathrm{M} \mathrm{KCl,} 25 \mathrm{mM}$ Tris-DCl in $\mathrm{D}_{2} \mathrm{O}$ at pD 7.6 (to account for the difference in the specific activity of $\mathrm{D}^{+}$versus $\left.\mathrm{H}^{+}\right) .{ }^{41}$ A small amount of $\alpha$-HL was then added and the current across the bilayer monitored using patch clamp apparatus to determine when a single pore had inserted in the membrane (Fig. S1 and S2, ESI $\dagger$ ). For experiments involving DNA, single-stranded DNA was added to the grounded side of the bilayer $(5 \mu \mathrm{l}$ of $300 \mu \mathrm{M})$ and a transmembrane potential of $120 \mathrm{mV}$ was applied.

Voltage-driven DNA events resulted in transient blockages in the free channel current $\left(I_{\mathrm{DNA}}\right)$ whose magnitude and duration $(\tau)$ were characteristic of the length of the strand and the type of event (Fig. 1b). ${ }^{30}$ Poly dT strands were used to prevent complications in the ion current signal arising from unwanted folding or dimerisation. Event data were pooled from at least five separate single-channel experiments for each experimental condition (i.e. using 30, 60 or 90 nucleotide DNA in either $\mathrm{D}_{2} \mathrm{O}$ or $\mathrm{H}_{2} \mathrm{O}$ buffer). These pooled datasets were compared by plotting the current blockage during DNA events (as defined in Fig. 1c) against the lifetime of each event $(\tau)$ (Fig. 2). Three clusters of event were visible for each set of experimental conditions shown in Fig. 2 that corresponded to events in which the DNA entered the pore vestibule and either escaped after a short period of time ( $\left.I^{*}{ }_{\text {vest }}\right)$, or threaded through the pore with $3^{\prime}$ - or $5^{\prime}$-first orientation $\left(I^{*}{ }_{3^{\prime}}\right.$ and $\left.I^{*}{ }^{\prime}\right){ }^{31,32}$ The clustered data were binned using Origin 9 Pro (3000-5000 events for each condition obtained over at least five different nanopore experiments) and the resulting histograms fitted to the Gaussian distributions that are shown along the edges of the scatter plots.

Ionic currents were found to be substantially lower in $\mathrm{D}_{2} \mathrm{O}$ than in $\mathrm{H}_{2} \mathrm{O}$ in both free $\alpha$-HL pores ( $I_{\text {free}}$ ) and during DNA vestibule and translocation events $\left(I_{\mathrm{DNA}}\right)$. Since an electrical current is a 
kinetic parameter, defined as the passage of charge per second, these differences in ionic current can be conveniently expressed as a $k_{\mathrm{H}} / k_{\mathrm{D}}$ ratio, which provides a standardised means of comparing isotope effects observed on the nanoscale with related bulk solvent properties. The structure of $\mathrm{D}_{2} \mathrm{O}$ is more ordered (and hence more viscous) than $\mathrm{H}_{2} \mathrm{O}$ and thus the energy barrier associated with the structural rearrangement of $\mathrm{D}_{2} \mathrm{O}$ is higher than in $\mathrm{H}_{2} \mathrm{O} .^{42,43}$ For example, $\mathrm{KCl}$ conductivity in bulk $\mathrm{H}_{2} \mathrm{O}$ is $21 \%$ higher than in $\mathrm{D}_{2} \mathrm{O}\left(k_{\mathrm{H}} / k_{\mathrm{D}}\right.$ of 1.21$),{ }^{12}$ which is related to the reciprocal of solvent viscosity $\left(k_{\mathrm{H}} / k_{\mathrm{D}}\right.$ of 1.23$) .{ }^{11}$ However, in the present study the current through the free nanopore in $\mathrm{KCl}$ solution ( $I_{\text {free }}$ ) gave a $k_{\mathrm{H}} / k_{\mathrm{D}} \approx 1.3$ (Fig. 3, left), corresponding to $\sim 10 \%$ enhancement of the solvent isotope effect on the passage of ions through the nanopore compared to bulk solution (values in Table S1, ESI $\dagger$ ). The solvent isotope effect on the current was consistent over the range of -100 to $+120 \mathrm{mV}$ indicating that there was little change in the selectivity of the ion translocation process for $\mathrm{K}^{+}$versus $\mathrm{Cl}^{-}$in $\mathrm{D}_{2} \mathrm{O}$ compared to $\mathrm{H}_{2} \mathrm{O}$ (Fig. S2, ESI $\dagger$ ). ${ }^{44}$

Due to the greater degree of solvent confinement within a nanopore blocked by DNA we reasoned that the ion current during DNA vestibule and translocation events $\left(I_{\text {DNA }}\right)$ might exhibit even greater divergence from bulk solvent isotope effects than that of the free pore $\left(I_{\text {free }}\right)$. The binned data for DNA events shown in Fig. 2 were used to determine $k_{\mathrm{H}} / k_{\mathrm{D}}$ for the average current flowing through the nanopore during vestibule and translocation events ( $\left.I_{\text {DNA }}\right)$.

Vestibule events involve only a slight current blockage and hence exhibit similar or slightly enhanced $k_{\mathrm{H}} / k_{\mathrm{D}}$ values to those seen for the free pore $\left(k_{\mathrm{H}} / k_{\mathrm{D}}=1.3\right.$ to 1.4 , up to $15 \%$ enhancement of the solvent isotope effect seen in free solution). It is known that 5 '-first and 3 '-first DNA translocation through $\alpha$-haemolysin pores occurs by distinct mechanisms as indicated by differing ion currents and blockage lifetimes. ${ }^{31,35}$ Ion currents during 5 -first DNA translocation were significantly decreased compared to the free channels and gave large $k_{\mathrm{H}} / k_{\mathrm{D}}$ ratios of up to 1.6, corresponding to a $35 \%$ enhancement of the solvent isotope effect compared to bulk solution (Fig. 3, centre). This large enhancement of the isotope effect during $5^{\prime}$-first translocations combined with the reduced ion current during these events is consistent with a high degree of solvent exclusion and solvent restructuring within the pore. A similarly large $k_{\mathrm{H}} / k_{\mathrm{D}}$ ratio for $I_{\text {DNA }}$ of $\sim 1.5$ was seen for $3^{\prime}$-first translocation for the shortest 30mer DNA, which was also associated with similar current blockage $\left(I_{\text {DNA }}=24 \mathrm{pA}\right.$ in $\mathrm{H}_{2} \mathrm{O}, 16 \mathrm{pA}$ in $\left.\mathrm{D}_{2} \mathrm{O}\right)$ to $5^{\prime}$-first $90 \mathrm{mer}$ translocation $\left(I_{\mathrm{DNA}}=28 \mathrm{pA}\right.$ in $\mathrm{H}_{2} \mathrm{O}, 18 \mathrm{pA}$ in $\left.\mathrm{D}_{2} \mathrm{O}\right)$.

However, the $k_{\mathrm{H}} / k_{\mathrm{D}}$ ratios of $I_{\mathrm{DNA}}$ during $3^{\prime}$-first translocations were highly dependent on the length of the DNA and fell to a value of $\sim 1.3$ for the 60 mer and only $\sim 1.1$ for 90 mer translocation (a 10\% reduction of the solvent isotope effect seen in the bulk). These reduced $k_{\mathrm{H}} / k_{\mathrm{D}}$ values were also associated with very small $I_{\mathrm{DNA}}$ values, consistent with a very high degree of solvent exclusion, which was greatest during translocation of the longest DNA molecules. Thus, we have established a qualitative link between the magnitude of the nanoscale solvent isotope effect and the extent of the current flowing through the pore during DNA events.
Plotting the average ion currents flowing through the nanopore against the solvent isotope effect gave the relationship shown in Fig. 4. Basic physics teaches us that electrical conductance is proportional to cross-sectional area. Thus, as a first approximation, the measured currents should be indicative of the conductive cross-sectional area of the nanopore during DNA events (see Fig. S5 and associated discussion in the ESI $\dagger$ ). Indeed, such a profile resembles previous computational models that describe the energetics of water confined within nanoscale spaces. ${ }^{45-47}$ Thus, we propose that the modulation of the solvent isotope effect on ion transport through nanopores by DNA is related to the dimensional constraints placed upon the formation of a solvent network compared to the bulk, and the influence of so-called "high-energy water". 7,45,48 The free pore has a diameter of $\sim 1.5 \mathrm{~nm},{ }^{23}$ which is large enough to accommodate up to six water molecules, but is sufficiently confined to give an enhancement of the solvent isotope effect $\left(k_{\mathrm{H}} / k_{\mathrm{D}} \approx 1.3\right)$ compared to the bulk $\left(k_{\mathrm{H}} / k_{\mathrm{D}} \approx 1.2\right)$. The maximum solvent isotope effect $\left(k_{\mathrm{H}} / k_{\mathrm{D}} \approx 1.6\right)$ was observed when $\sim 75 \%$ of the conductive channel was blocked, but below this a critical threshold is reached where so much solvent is excluded from the pore that not enough remains for a solvent isotope effect to be exhibited.

While the $k_{\mathrm{H}} / k_{\mathrm{D}}$ ratio of $I_{\mathrm{DNA}}$ discussed above is dominated by events occurring inside the pore, the $k_{\mathrm{H}} / k_{\mathrm{D}}$ ratio derived from the rate of DNA translocation, $k_{\mathrm{DNA}}$ (Fig. 3, right) is also influenced by the effects of the bulk solvent. Indeed, previous experiments have shown that the rate of DNA translocation through nanopores scales with bulk solvent viscosity upon the addition of glycerol. ${ }^{39,40}$ As a result, the $k_{\mathrm{H}} / k_{\mathrm{D}}$ ratios for the rate of DNA translocation tended towards that of the bulk $\left(k_{\mathrm{H}} / k_{\mathrm{D}} \approx 1.2\right)$, particularly for the longest 90mer strands. The change in the relative contribution of these two environments (inside and outside the pore) may also explain the inflection seen in the $k_{\mathrm{H}} / k_{\mathrm{D}}$ ratios for the rates of $3^{\prime}$-first DNA translocation. Furthermore, multiple factors including steric, electrostatic and electro-osmotic effects may all influence the translocation of biopolymers through $\alpha$-HL nanopores. ${ }^{49}$

Additional experiments were performed in a 1:1 mixture of $\mathrm{H}_{2} \mathrm{O}$ and $\mathrm{D}_{2} \mathrm{O}$ buffers, 'HDO'. The behaviour in 'HDO' was intermediate between that seen in the $\mathrm{H}_{2} \mathrm{O}$ and $\mathrm{D}_{2} \mathrm{O}$ buffers, but closer to the behaviour observed in $\mathrm{D}_{2} \mathrm{O}$ buffer (Table $\mathrm{S} 1$ and Fig. S2, ESI $\dagger$ ). The free pore current, $I_{\text {free }}$ was commensurate with the effects of viscosity in previous nanopore studies performed with water-glycerol mixtures (Fig. S2c, ESI $\dagger$ ). ${ }^{39}$

In summary, we have investigated the modulation of solvent isotope effects within individual $\alpha$-haemolysin nanopores by DNA (Fig. 1 and 2). $\mathrm{D}_{2} \mathrm{O}$ was found to retard both ion and DNA translocation through nanopores compared to $\mathrm{H}_{2} \mathrm{O}$, but the magnitude of the nanoscale isotope effects was found to differ compared to equivalent processes occurring in the bulk $\left(k_{\mathrm{H}} / k_{\mathrm{D}} \approx 1.2\right)$. In some cases the isotope effect was found to be enhanced, from $k_{\mathrm{H}} / k_{\mathrm{D}} \approx 1.3$ for the free pore, to $k_{\mathrm{H}} / k_{\mathrm{D}} \approx 1.6$ during the translocation of DNA (Fig. 3). However, a diminished nanoscale solvent isotope effect $\left(k_{\mathrm{H}} / k_{\mathrm{D}} \approx 1.1\right)$ was associated with DNA translocation events that gave near-complete current blockage. This contrasting behaviour was related to the effective conductive cross-section of the pore 
and hence to the degree of solvent exclusion from the pore (Fig. 4). Nanoscale solvent isotope effects might be more widely exploited in single-molecule investigations of conformationally dynamic biomolecules and synthetic molecular machines, ${ }^{17,50,51}$ or as a means of modulating the signal in nanopore DNA sequencing technologies. $^{15,38}$

This research was supported by the Engineering and Physical Sciences Research Council (EP/H021620-1) and ERC Starting Grant No. 336935, TransporeT.

\section{Notes and references}

1 F. H. Westheimer, Chem. Rev., 1961, 61, 265-273.

2 C. R. Pudney, R. S. K. Lane, A. J. Fielding, S. W. Magennis, S. Hay and N. S. Scrutton, J. Am. Chem. Soc., 2013, 135, 3855-3864.

3 S. Scheiner and M. Cuma, J. Am. Chem. Soc., 1996, 118, 1511-1521.

4 J. S. Mugridge, R. G. Bergman and K. N. Raymond, J. Am. Chem. Soc., 2011, 134, 2057-2066.

5 J. S. Mugridge, R. G. Bergman and K. N. Raymond, Angew. Chem., Int. Ed., 2010, 49, 3635-3637.

6 T. Felder and C. A. Schalley, Angew. Chem., Int. Ed., 2003, 42, 2258-2260.

7 F. Biedermann, M. Vendruscolo, O. A. Scherman, A. De Simone and W. M. Nau, J. Am. Chem. Soc., 2013, 135, 14879-14888.

8 M. I. Franco, L. Turin, A. Mershin and E. M. C. Skoulakis, Proc. Natl. Acad. Sci. U. S. A., 2011, 108, 3797-3802.

9 A. Keller and L. B. Vosshall, Nat. Neurosci., 2004, 7, 337-338.

10 The IUPAC definition of solvent isotope effect is "A kinetic or equilibrium isotope effect resulting from change in the isotopic composition of the solvent", which includes effects on physical properties or supramolecular processes in which no covalent bonds are broken or formed.

11 K. R. Harris and L. A. Woolf, J. Chem. Eng. Data, 2004, 49, 1064-1069.

12 C. G. Swain and D. F. Evans, J. Am. Chem. Soc., 1966, 88, 383-390.

13 K. Altwegg, H. Balsiger, A. Bar-Nun, J. J. Berthelier, A. Bieler, P. Bochsler, C. Briois, U. Calmonte, M. Combi, J. De Keyser, P. Eberhardt, B. Fiethe, S. Fuselier, S. Gasc, T. I. Gombosi, K. C. Hansen, M. Hässig, A. Jäckel, E. Kopp, A. Korth, L. LeRoy, U. Mall, B. Marty, O. Mousis, E. Neefs, T. Owen, H. Rème, M. Rubin, T. Sémon, C.-Y. Tzou, H. Waite and P. Wurz, Science, 2015, 347, 1261952.

14 R. D. Astumian, Phys. Chem. Chem. Phys., 2007, 9, 5067-5083.

15 E. R. Kay, D. A. Leigh and F. Zerbetto, Angew. Chem., Int. Ed., 2007, 46, 72-191.

16 P. Cioni and G. B. Strambini, Biophys. J., 2002, 82, 3246-3253.

17 J. Lisal, T. T. Lam, D. E. Kainov, M. R. Emmett, A. G. Marshall and R. Tuma, Nat. Struct. Mol. Biol., 2005, 12, 460-466.

18 C. L. Schauf and J. O. Bullock, Biophys. J., 1982, 37, 441-452.

19 C. L. Schauf and J. O. Bullock, Biophys. J., 1979, 27, 193-208.

20 T. E. DeCoursey and V. V. Cherny, J. Gen. Physiol., 1997, 109, 415-434.

21 W. Choi, Z. W. Ulissi, S. F. E. Shimizu, D. O. Bellisario, M. D. Ellison and M. S. Strano, Nat. Commun., 2013, 4, 2397.

22 J. K. Holt, H. G. Park, Y. Wang, M. Stadermann, A. B. Artyukhin, C. P. Grigoropoulos, A. Noy and O. Bakajin, Science, 2006, 312, 1034-1037.
23 L. Song, M. R. Hobaugh, C. Shustak, S. Cheley, H. Bayley and J. E. Gouaux, Science, 1996, 274, 1859-1865.

24 H.-C. Wu and H. Bayley, J. Am. Chem. Soc., 2008, 130, 6813-6819.

25 S.-H. Shin, T. Luchian, S. Cheley, O. Braha and H. Bayley, Angew. Chem., Int. Ed., 2002, 41, 3707-3709.

26 G. M. Cherf, K. R. Lieberman, H. Rashid, C. E. Lam, K. Karplus and M. Akeson, Nat. Biotechnol., 2012, 30, 344-348.

27 S. L. Cockroft, J. Chu, M. Amorin and M. R. Ghadiri, J. Am. Chem. Soc., 2008, 130, 818-820.

28 J. Chu, M. González-López, S. L. Cockroft, M. Amorin and M. R. Ghadiri, Angew. Chem., Int. Ed., 2010, 49, 10106-10109.

29 J. Nivala, D. B. Marks and M. Akeson, Nat. Biotechnol., 2013, 31, 247-250.

30 J. J. Kasianowicz, E. Brandin, D. Branton and D. W. Deamer, Proc. Natl. Acad. Sci. U. S. A., 1996, 93, 13770-13773.

31 J. Mathé, A. Aksimentiev, D. R. Nelson, K. Schulten and A. Meller, Proc. Natl. Acad. Sci. U. S. A., 2005, 102, 12377-12382.

32 T. Z. Butler, J. H. Gundlach and M. Troll, Biophys. J., 2007, 93, 3229-3240.

33 D. Stoddart, A. J. Heron, E. Mikhailova, G. Maglia and H. Bayley, Proc. Natl. Acad. Sci. U. S. A., 2009, 106, 7702-7707.

34 A. Meller, L. Nivon, E. Brandin, J. Golovchenko and D. Branton, Proc. Natl. Acad. Sci. U. S. A., 2000, 97, 1079-1084.

35 H. Wang, J. E. Dunning, A. P.-H. Huang, J. A. Nyamwanda and D. Branton, Proc. Natl. Acad. Sci. U. S. A., 2004, 101, 13472-13477.

36 S. Lu, W.-W. Li, D. Rotem, E. Mikhailova and H. Bayley, Nat. Chem., 2010, 2, 921-928.

37 J. J. Kasianowicz and S. M. Bezrukov, Biophys. J., 1995, 69, 94-105.

38 D. Branton, D. W. Deamer, A. Marziali, H. Bayley, S. A. Benner, T. Butler, M. Di Ventra, S. Garaj, A. Hibbs, X. Huang, S. B. Jovanovich, P. S. Krstic, S. Lindsay, X. S. Ling, C. H. Mastrangelo, A. Meller, J. S. Oliver, Y. V. Pershin, J. M. Ramsey, R. Riehn, G. V. Soni, V. Tabard-Cossa, M. Wanunu, M. Wiggin and J. A. Schloss, Nat. Biotechnol., 2008, 26, 1146-1153.

39 R. Kawano, A. E. P. Schibel, C. Cauley and H. S. White, Langmuir, 2009, 25, 1233-1237.

40 D. Fologea, J. Uplinger, B. Thomas, D. S. McNabb and J. Li, Nano Lett., 2005, 5, 1734-1737.

41 A. K. Covington, M. Paabo, R. A. Robinson and R. G. Bates, Anal. Chem., 1968, 40, 700-706.

42 G. Graziano, J. Chem. Phys., 2004, 121, 1878-1882.

43 G. Némethy and H. A. Scheraga, J. Chem. Phys., 1964, 41, 680-689.

44 M. Misakian and J. J. Kasianowicz, J. Membr. Biol., 2003, 195, 137-146.

45 T. A. Pascal, W. A. Goddard and Y. Jung, Proc. Natl. Acad. Sci. U. S. A., 2011, 108, 11794-11798.

46 D. Chandler, Nature, 2005, 437, 640-647.

47 G. Hummer, J. C. Rasaiah and J. P. Noworyta, Nature, 2001, 414, 188-190.

48 F. Biedermann, W. M. Nau and H.-J. Schneider, Angew. Chem., Int. Ed., 2014, 53, 11158-11171.

49 S. F. Buchsbaum, N. Mitchell, H. Martin, M. Wiggin, A. Marziali, P. V. Coveney, Z. Siwy and S. Howorka, Nano Lett., 2013, 13, 3890-3896.

50 M. R. Panman, B. H. Bakker, D. den Uyl, E. R. Kay, D. A. Leigh, W. J. Buma, A. M. Brouwer, J. A. J. Geenevasen and S. Woutersen, Nat. Chem., 2013, 5, 929-934.

51 G. S. Pulcu, E. Mikhailova, L.-S. Choi and H. Bayley, Nat. Nanotechnol., $2015,10,76-83$. 